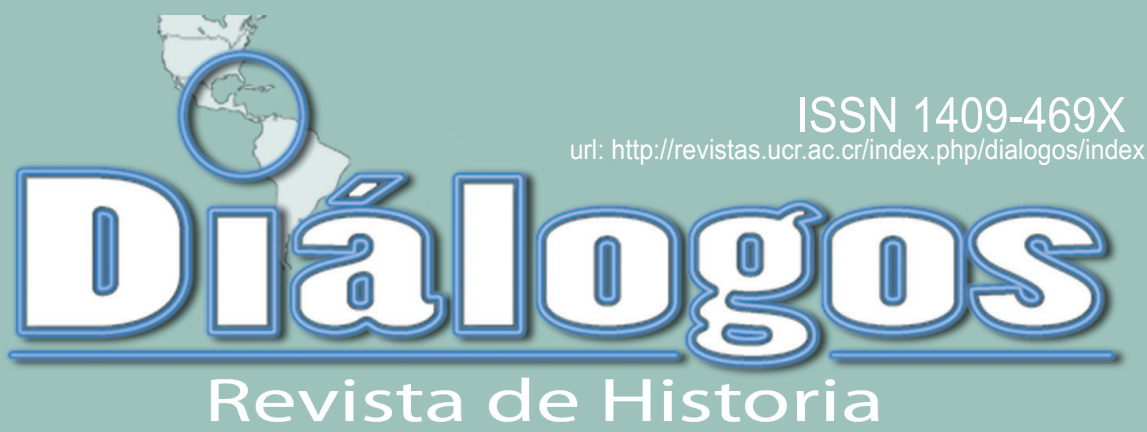

Escuela de Historia. Universidad de Costa Rica Vol. 15 No. 2 Setiembre 2014 - Enero 2015

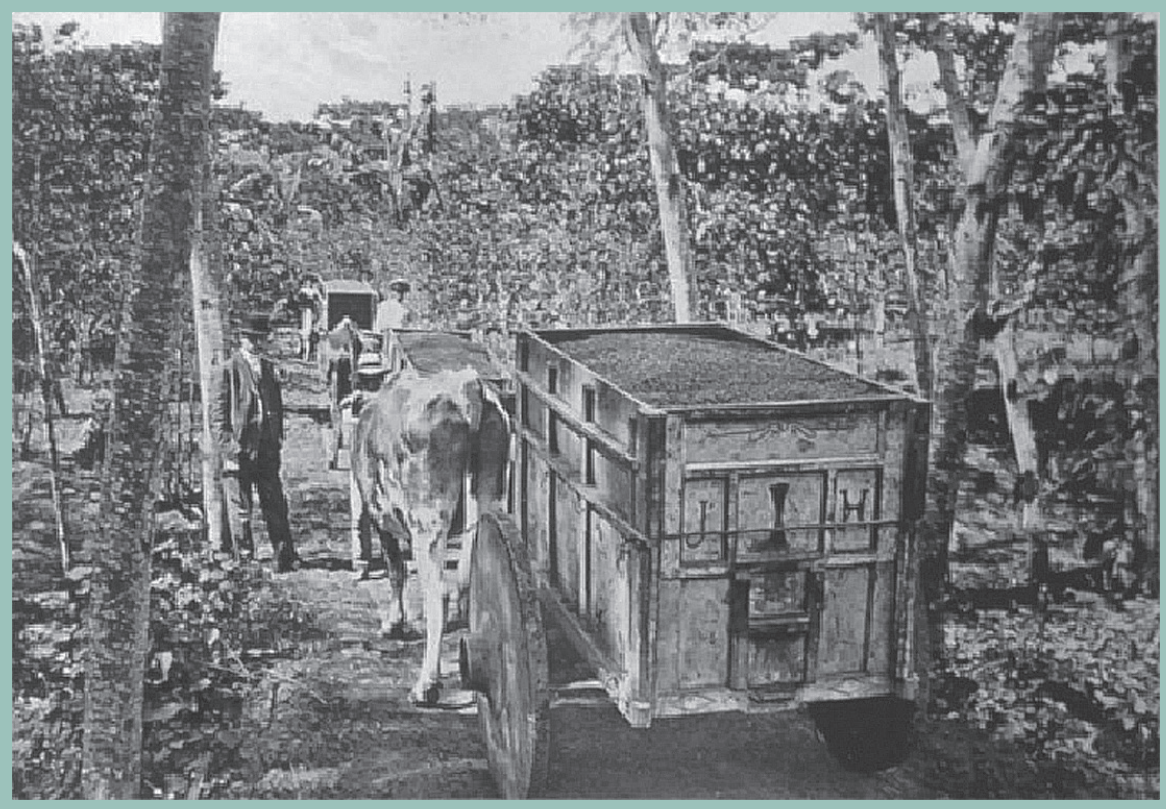

Director de la Revista: Dr. Juan José Marín Hernández juan.marinhernandez@ucr.ac.cr

Editor académico: Dr. David Díaz Arias - david.diaz@ucr.ac.cr Editor técnico: M.Sc. Marcela Quirós G. - marcela.quiros@ucr.ac.cr

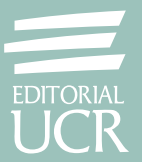


RESEÑAS 



\title{
PABLO POZZI Y CLAUDIO PÉREZ (EDITORES), POR EL CAMINO \\ DEL CHE. LAS GUERRILLAS LATINOAMERICANAS, 1959-1990. UNIVERSIDAD DE BUENOS AIRES - UNIVERSIDAD ACADEMIA DE HUMANISMO CRISTIANO - RED LATINOAMERICANA DE HISTORIA ORAL - IMAGO MUNDI, BUENOS AIRES, 2012. (458 PÁGINAS)
}

\author{
PABLO POZZI Y CLAUDIO PÉREZ (EDS.), BY THE WAY CHE. LATIN AMERICAN \\ GUERRILLAS, 1959-1990. UNIVERSIDAD DE BUENOS AIRES - UNIVERSIDAD \\ ACADEMIA DE HUMANISMO CRISTIANO - RED LATINOAMERICANA DE HISTORIA \\ ORAL - IMAGO MUNDI, BUENOS AIRES, 2012. (458 PAGES)
}

Marcelo Alejandro Bonnassiolle Cortés

El libro Por el camino del Che. Las guerrillas latinoamericanas, 1959-1990, es uno de los más significativos e importantes aportes de las últimas décadas a la historiografía política latinoamericana y pasará a constituirse como material de consulta obligatoria para quienes tratan temáticas propias de la historia reciente del continente, principalmente relacionadas con los movimientos de izquierda $\mathrm{y}$, tal como dicta su título, las guerrillas y la lucha armada en la región.

La obra es el resultado de la participación de sus autores en el grupo de trabajo CLACSO: Violencia y política. Historia oral e historia política. Estudiar la izquierda latinoamericana, y aborda la experiencia de la izquierda revolucionaria a través de uno de sus aspectos más conflictivos: la violencia política y la lucha armada, por lo cual, el estudio de sus organizaciones, expresiones políticas, militares y las estrategias que utilizaba, ocupa un lugar fundamental en la publicación.

A lo largo de más de cuatrocientas páginas se encuentran trece artículos de autores nacionales y extranjeros, quienes escriben sobre distintos grupos guerrilleros y organizaciones político-militares, urbanas y rurales; locales y nacionales, que se configuraron en América Latina a lo largo de un período que abarca desde la década de 1960 hasta 1990, época marcada por la inestabilidad política y la conflictividad social, así como también por la radicalización voluntaria de cientos de hombres y mujeres, quienes motivados por el impacto en la región de las luchas anticoloniales y antiimperialistas, tales como la revolución cubana y la guerra de Vietnam, y por la figura del Che Guevara; decidieron combatir por la transformación radical del continente.

Lo anterior modificó y readaptó las estrategias y tácticas de lucha de la izquierda latinoamericana, tanto en el ámbito cultural como político, de ahí que la idea de la 
revolución social y el surgimiento de dichos grupos y organizaciones configuraron a "la nueva izquierda" o izquierda revolucionaria, la cual, a través de la violencia política y la lucha armada, vio la posibilidad de realizar cambios estructurales en la sociedad, para avanzar en la construcción del socialismo.

Por todo lo antes expuesto es que las principales categorías de análisis que convergen en el texto son, por una parte, la violencia política, la cual puede ser comprendida como una herramienta teórica y táctica para la transformación radical de la sociedad y, por ende en "un elemento central para analizar las dinámicas sociales y políticas que tensionan y caracterizan a una sociedad en pleno proceso de cambio"(Pozzi y Pérez, 2012, p IX) según los autores; y por otra parte la politización o radicalización voluntaria, ya que el surgimiento y configuración de las organizaciones políticas militares y los grupos guerrilleros claramente implicó que los jóvenes, desde distintas perspectivas y estrategias, participaran en discusiones sobre los repertorios, las herramientas y tácticas necesarias para alcanzar el socialismo y de esta manera, el desarrollo de una transformación radical de las distintas sociedades latinoamericanas, todas marcadas por las injusticias y la desigualdad.

En este contexto surgieron nuevos grupos de activistas y militantes con características propias, dependiendo de cada grupo y experiencia histórica; sin embargo todos unidos por aspectos culturales -una estructura de sentimientos, según los autores-, que se traducían en un lenguaje, un simbolismo y en prácticas que tenían fuertes elementos en común y de continuidad histórico-política. Si bien es posible identificarlos con la idea de efectuar un cambio radical de índole social o político, los investigadores hacen una distinción entre ambos actores; ya que según ellos el activista es aquel individuo que se desempeña principalmente en la organización social y se diferencia del militante en que este último tiene la política como eje primordial de su actividad.

Resulta interesante destacar la división que proponen los autores del desarrollo de la guerrilla latinoamericana en tres etapas: un primer periodo es el de foco o foquismo (1959-1969) marcado por la influencia guevarista, principalmente a través de la militarización de la política; un segundo periodo es el de las organizaciones político-militares (1970-1979) marcado por la combinación de la lucha armada con el trabajo de masas, y un tercer periodo (1980-1999) en el cual la vía armada se consolidó como forma de lucha de otras organizaciones políticas.

También se destaca que todos los artículos de la publicación se encuentran enmarcados en el estudio de casos particulares a nivel local-nacional y sólo a través de la lectura completa del libro es posible, en palabras de sus autores, desarrollar una mirada "latinoamericana" del proceso de construcción de "la nueva izquierda" revolucionaria y la lucha armada en el continente. De ahí que, preguntas como ¿Quiénes eran los revolucionarios?, ¿Quiénes participaron en los 
grupos de guerrilleros? o ¿Cuáles eran sus objetivos y estrategias? son tratadas con profundidad por los diversos colaboradores, bajo el patrón común del estudio del período, desde la óptica del análisis de la lucha armada y la violencia política y revolucionaria.

A lo largo de la publicación se tratan, por ejemplo, casos como la construcción de la identidad política en la Alianza Popular Revolucionaria Americana (APRA) y el Movimiento de Izquierda Revolucionaria (MIR), en Perú; las rupturas y continuidades en el Ejército de Liberación Nacional (ELN) y su sucesor, el Partido Revolucionario de los Trabajadores de Bolivia (PRT-B), en Bolivia; la participación de combatientes puertorriqueños y sus incursiones guerrilleras en la República Dominicana durante la dictadura de Rafael Leónidas Trujillo en 1959; del Ejército de Liberación Nacional (ELN) y las FARC, en Colombia; la incidencia de la lucha armada y la violencia política a través de los casos del Movimiento de Izquierda Revolucionaria (MIR), el MAPU-LAUTARO y el Frente Patriótico Manuel Rodríguez (FPMR), en Chile; los Uturuncos y la izquierda peronista en Argentina; el Movimiento Armado Socialista en México y el Movimiento de Liberación Nacional Tupamaros en Uruguay; todos los cuales nos permiten dimensionar desde lo particular a lo general la actividad política, las diversas dinámicas, experiencias y trayectorias, al igual que apreciar la heterogeneidad de los distintos grupos políticomilitares y experiencias guerrilleras que emergieron en el continente en aquellas conflictivas décadas.

Sin embargo, no sólo destaca este libro por la diversidad y propuestas de sus artículos, sino también por la calidad de sus investigaciones y la metodología utilizada, ya que las fuentes de la época, principalmente documentos partidarios y prensa, son complementadas con testimonios orales, lo que permite a los autores acercarse a las subjetividades de quienes participaron en dichos grupos. Si se toma en consideración el importante papel que ocupó la clandestinidad en la configuración de la izquierda revolucionaria, el complemento y contrastación de las fuentes documentales con los testimonios orales permiten, de manera fructífera, la incorporación de nuevos enfoques que contribuyen al enriquecimiento y renovación de la historia política, además de posibilitar nuevas temáticas y ópticas de interpretación del pasado.

Todo lo anterior, y como bien lo han puntualizado sus autores, hace emerger desde los artículos una serie de reflexiones, propuestas, cuestionamientos y debates que suscitarán nuevos enfoques en las actuales interpretaciones de la izquierda latinoamericana. Importante es tomar en consideración la persistencia en el tiempo de la izquierda, al igual que las dimensiones alcanzadas en el continente. Esto puede ser explicado por la capacidad de adaptarse y replantearse según determinados contextos y períodos históricos; por lo cual, y como bien se demuestra en la publicación, la emergencia de la "nueva izquierda" revolucionaria tiene sus raíces en el 
escenario continental y no en pequeñas vanguardias o grupos aislados. De ahí que la utilización y legitimación de la violencia revolucionaria sería una estrategia de lucha contra la hegemonía de la clase dominante, lograda a través de la violencia.

Finalmente, el libro representa una contribución historiográfica significativa e importante para el estudio de los movimientos de izquierda y la lucha armada en América Latina, y sus autores no sólo entregan el material documental necesario para comprender y analizar aquellos procesos revolucionarios de la historia reciente del continente, sino que también abren nuevos y enriquecedores debates y propuestas sobre la experiencia de los movimientos guerrilleros y las organizaciones político-militares que marcaron la actividad política y la lucha armada en el continente. Todo lo cual nos invita a reflexionar principalmente sobre cuál es el papel de la violencia y la lucha armada en América Latina.

Santiago de Chile, febrero de 2014.

\section{CITAS Y NOTAS}

1 Pozzi, P. y Pérez, C. (Eds.) (2012). Por el camino del Che. Las guerrillas americanas, 19591990. Universidad de Buenos Aires. Universidad Academia de Humanismo Cristiano. Red Latinoamericana de Historia Oral. Argentina: Imago Mundi. p. IX.

\section{ACERCA EL AUTOR}

Marcelo Alejandro Bonnassiolle Cortés: Estudiante de Magíster en Historia. Universidad de Santiago de Chile. Periodo 2013 -2014. Investigador del Centro de Documentación e Investigación de Historia Reciente, Escuela de Historia. Universidad Academia de Humanismo Cristiano. Líneas de interés e Investigación: Historia Contemporánea. Historia social y política de Chile, siglos XIX y XX. Militancias, partidos políticos y movimientos sociales. Santiago de Chile, correo electrónico: mbonnc@gmail.com 